\title{
Characterization of Extruded Poly(lactic acid)/Pecan Nutshell Biocomposites
}

\author{
C. R. Álvarez-Chávez, ${ }^{1,2,3}$ D. L. Sánchez-Acosta, ${ }^{2}$ J. C. Encinas-Encinas, ${ }^{4}$ \\ J. Esquer, ${ }^{2,3}$ P. Quintana-Owen, ${ }^{5}$ and T. J. Madera-Santana ${ }^{6}$ \\ ${ }^{1}$ Chemical and Biological Sciences Department, University of Sonora, Rosales y Luis Encinas, Col. Centro, 83000 Hermosillo, \\ SON, Mexico \\ ${ }^{2}$ Sustainability Graduate Program, Industrial Engineering Department, University of Sonora, Hermosillo, SON, Mexico \\ ${ }^{3}$ Department of Public Health, University of Massachusetts Lowell, Lowell, MA, USA \\ ${ }^{4}$ Polymers and Materials Research Department, University of Sonora, Hermosillo, SON, Mexico \\ ${ }^{5}$ Research Center and Advanced Studies of IPN, Mérida Unit, Ant. Carr. a Progreso Km. 6, Apdo. Postal 73, Cordemex, 97310 Mérida, \\ YUC, Mexico \\ ${ }^{6}$ Research Center for Food and Development, CTAOV, Hermosillo, SON, Mexico
}

Correspondence should be addressed to T. J. Madera-Santana; madera@ciad.mx

Received 27 March 2017; Revised 24 May 2017; Accepted 1 June 2017; Published 12 July 2017

Academic Editor: Maria Laura Di Lorenzo

\begin{abstract}
Copyright (C) 2017 C. R. Álvarez-Chávez et al. This is an open access article distributed under the Creative Commons Attribution License, which permits unrestricted use, distribution, and reproduction in any medium, provided the original work is properly cited.

Pecan nutshells are a solid form of waste obtained from the pecan nut production and they have been explored as an inexpensive filler for incorporation by melt blending into the poly(lactic acid) (PLA) matrix. The pecan nutshells contain polyphenols, proteins, tannins, sugars, and lipids; some of these components must be released in order to improve adhesion with a polymeric matrix. The physicochemical characterization of the extruded biocomposites of pecan nutshell powder (PNSP) at 0,5 , and $7.5 \%$ wt. with two treatments (untreated and defatted) into PLA is presented in this work. The incorporation of PNSP into the PLA matrix caused a variation in color and density and increased the water absorption. However, some mechanical and thermal parameters of the biocomposites showed a significant decrease. The morphological analysis showed good dispersion and adhesion of the PNSP to the PLA matrix. Based on the results of the characterization, biocomposites formulated with defatted PNSP have a potential to be used as sustainable fillers in PLA biocomposites. These biocomposites have a potential application as food containers, packaging trays, or disposable items.
\end{abstract}

\section{Introduction}

Agricultural residues represent a wide variety of waste materials produced from the agriculture and food industries that can cause serious pollution problems. Several studies have reported the use of biomass wastes as natural fillers in polymeric composites [1-3]. These composite materials are reinforced with natural fillers and fibers, such as peanuts shells, nuts, rice, coconut, and wood [4-6] and have low costs and density, good thermal insulation, strength, acceptable resistance, and abundant availability in certain regions $[7,8]$.

The poly(lactic acid) (PLA) is one of the most developed biodegradable bioplastics from a technological point of view [9]. It is a semicrystalline, transparent, high strength biopolymer synthesized from the polymerization of the lactic acid monomer, which is obtained from corn, sugarcane, beet, and other products rich in starch [10]. This biopolymer has excellent optical and mechanical properties, but its thermomechanical characteristics limit its use in different fields [11, 12]. Hence, it is desirable to use fillers of a natural origin that do not affect the biodegradability of the PLA matrix. The incorporation of natural fillers to the PLA and other polymer matrices has been reported by some authors $[3,5,13-17]$. Some aspects, such as cost reduction, along with an improvement in the physical, chemical, mechanical, and thermal properties, are motivating the development of the 
biocomposites in order to reduce the use of synthetic plastics obtained from the oil.

The pecan nutshells are a renewable lignocellulosic source obtained as an agricultural byproduct. The pecan nutshell covers the pecan nut [Carya illinoinensis (Wangenh) C. Koch] and this fruit belongs to the family Juglandaceae from North American countries (USA and Mexico). In Mexico, the production of pecan nuts accounted for 38,660 tons in 2016. In order to consume the pecan nut, several operations are to be considered, such as, grading and sizing, cracking, shelling, and drying. Around $50 \%$ of the weight of a pecan nut is constituted by its shell, which is a byproduct. Finely ground pecan nutshells are used as an organic abrasive product for cleaning, polishing, and deburring metallic or plastic parts. The automotive industry uses nutshells in powders in order to clean engines without scratching their surface, whereas the cosmetic industry uses them as exfoliating agents in face, body, and feet cleaners. Some authors have reported that nutshells can be used as filler in the biocomposites of various applications where a high dimensional stability is required $[7,13]$. Moreover, the pecan nutshell powder (PNSP) is a hydrophilic biofiller that contains cellulose, lignin, tannins, and hemicelluloses. The presence of hydroxyl groups in the molecules of the lignocellulosic macromolecules causes a difficult interfacial interaction between the natural filler and the polymer matrix [18]. Therefore, solvent extraction (hexane, chloroform, ethanol, etc.) using the soxhlet method is a common lab procedure implemented in order to remove impurities (waxes, lipids, tannins, and low molecular lignin) from biofillers.

The mechanical and thermal properties of the biocomposites containing particulate fillers show a strong dependence on the particle size, particle loading, interface adhesion, and homogenization of the filler in the polymeric matrix [19]. Another important factor is the type of mixing between the matrix and the filler, noting that the polymer matrix must completely embed the filler particles, thus preventing the separation of the body components [20]. An extrusion process is ideal in order to fabricate biocomposites with good homogenization, because this procedure can melt the polymer matrix while being mixed with the particulate filler passing through a screw process. This processing technique has been used since the 1950s, but its application in biocomposites when using biodegradable matrices is recent [21]. In this regard, Tisserat et al. discussed the limitations of moisture in the particulate fillers used in the extrusion process and reported that a reduction of the moisture content improves the interaction particle-matrix [22]. Considering these factors, the properties of the biocomposites can be modified as needed and in accordance with the required application, such as food containers, packaging trays, or cutlery.

The objective of this study is to produce biocomposites formulated with PNSP and PLA by means of extrusion. The treatment used to remove the impurities from the PNSP was the soxhlet extraction method. The effect of the PNSP treatments on the mechanical, structural, thermal, and morphological properties of the biocomposites is reported. The present paper is the first report that analyzes the effect of the degreasing treatment of the PNSP on the adhesion in a PLA matrix. It is important to point out that the PNSP is a byproduct from the pecan nut industry that generates high volumes and is regarded as a waste pollutant that is damaging the environment.

\section{Experimental}

2.1. Materials. The material used in this work was pecan nutshell [Carya illinoinensis (Wangenh) C. Koch] powder (PNSP) provided by Nuez Pecanera, S.A (Mexico). The PNSP was sieved using an 80 mesh and part of this powder was defatted using the soxhlet extraction method using hexane (Sigma-Aldrich). As a polymeric matrix, poly(lactic acid) (PLA) from Ingeo Biopolymer, grade 2003D, was supplied by NatureWorks, Inc.

2.2. Preparation of the Biocomposites. Pellets of PLA were reduced in size using a Thomas Wiley mill model 4 and the milled material was sieved with a mesh of $2 \mathrm{~mm}$. The PNSP samples, untreated and defatted, were dried in an air convection oven at $60^{\circ} \mathrm{C}$, until the moisture content reached less than $1 \% \mathrm{wt}$. The biocomposites of the PLA with 0,5 , and $7.5 \%$ wt. of PNSP (untreated and defatted) were physically mixed in a plastic bag. Each formulation was processed using a single screw minilaboratory extruder from Polymer Evaluation Products model ATLAS (Chicago, IL), with a temperature profile of $145^{\circ} \mathrm{C}$ (feed zone) and $160^{\circ} \mathrm{C}$ (die zone). The extruder shaft $(\approx 1 \mathrm{~cm}$ diameter $)$ was rotated at $60 \mathrm{rpm}$. The sheet ( $5 \mathrm{~cm}$ wide and $0.2 \mathrm{~cm}$ thick) was collected with a stainless steel idler roll. Finally, all the biocomposites obtained were stored in plastic bags, before testing.

2.3. Color Measurements. The color measurements of the PLA-PNSP biocomposites were performed using a Konica Minolta CR-300 colorimeter calibrated with a standard series $(Y=92.4, x=0.3161$, and $y=0.3324)$. The measurement was performed by placing the sample over the standard. The luminosity determined by $L^{*}$ and the chrome coordinates $a^{*}$ (red-green) and $b^{*}$ (yellow-blue) were used to calculate the chroma $\left(C^{*}\right)$, hue angle $\left(h^{\circ}\right)$, and color difference $(\Delta E)$, by (1), (2), and (3), respectively. Ten measurements were performed on each sample and the average values were obtained.

$$
\begin{aligned}
C^{*} & =\sqrt{a^{* 2}+b^{* 2}}, \\
h^{\circ} & =\arctan \left(\frac{b^{*}}{a^{*}}\right), \\
\Delta E & =\sqrt{\left(\Delta L^{*}\right)^{2}+\left(\Delta a^{*}\right)^{2}+\left(\Delta b^{*}\right)^{2}},
\end{aligned}
$$

where $\Delta L^{*}=L^{*}-L_{0}^{*}, \Delta a^{*}=a^{*}-a_{0}^{*}$, and $\Delta b^{*}=b^{*}-b_{0}^{*}, L_{0}^{*}$, $a_{0}^{*}$, and $b_{0}^{*}$, represent the color parameter values of the neat PLA, and $L^{*}, a^{*}$, and $b^{*}$ represent the color parameters of the sample. Measurements were performed by placing the film sample over the standard. All of the samples were analyzed by recording six measurements for each sample. 
2.4. Identification of the Functional Groups. The identification of the functional groups was performed using an infrared Fourier transform (FTIR) spectrophotometer Perkin Elmer model Spectrum GX (Mexico), in the attenuated total reflection (ATR) mode. The PLA-PNSP biocomposites were analyzed in a spectral range from 4000 to $400 \mathrm{~cm}^{-1}$ with $4 \mathrm{~cm}^{-1}$ resolution.

2.5. Water Absorption. The PLA-PNSP biocomposites were cut into specimens of $1.3 \mathrm{~cm}$ in width and $5 \mathrm{~cm}$ in length, and each sample was weighted with a Mettler Toledo model MS303S (Switzerland) precision balance. These samples were placed at constant weight, $\left(w_{i}\right)$ before being introduced into containers with $100 \mathrm{~mL}$ of distilled water. At specific intervals of time, the samples were released from the container and superficial water was released using absorbent paper. The total immersion time of the samples was up to $120 \mathrm{~min}$. The percentage change in weight or the water absorbed $\left(w_{f}\right)$ was calculated with the following equation:

$$
\text { Water absorption }(\%)=\frac{w_{f}-w_{i}}{w_{i}} \times 100 \text {. }
$$

This test was performed in triplicate for each formulation and the average water absorption values were calculated.

2.6. Density. The density was determined from the weight and volume of each biocomposite sample. The biocomposite samples were dried at $60^{\circ} \mathrm{C}$ in an air convection oven, until a constant weight was achieved. The samples were weighed using a Mettler Toledo model MS303S (Switzerland) precision balance. The dimensions of each sample $(1.3 \mathrm{~cm}$ in width and $5 \mathrm{~cm}$ in length, approximately) were measured using a Mitutoyo digital vernier model CD-6" CSX (Japan) and were used in order to calculate their volume. The density was calculated on the basis of the following equation:

$$
\text { Density }=\frac{M_{0}}{V_{0}},
$$

where $M_{0}$ is the dry weight in grams and $V_{0}$ is the volume of each of the samples in $\mathrm{cm}^{3}$.

2.7. Mechanical Tests. The tensile tests of the biocomposites were determined using a universal testing machine United model SSTM-5KN (Huntington Beach, CA). The tests were conducted according to the ASTM method D882 in rectangular shape $(10 \mathrm{~mm} \times 70 \mathrm{~mm})$, using a crosshead speed of $1 \mathrm{~mm} / \mathrm{min}$. The mechanical parameters evaluated were the tensile strength, elongation at break, and the tensile modulus; the number of the specimens tested was at least six for each formulation. Mechanodynamic tests were performed following ASTM D5026 (tension method), using a Perkin Elmer DMA model 8000 (Waltham, MA), under the following conditions: the temperature range used was from 0 to $100^{\circ} \mathrm{C}$, followed by a heating rate of $3^{\circ} \mathrm{C} / \mathrm{min}$ and a frequency value of $1 \mathrm{~Hz}$.

2.8. Thermal Characterization. The thermal decomposition analyses were conducted using a thermogravimetric analyzer
(TGA) from TA Instruments Inc. model Discovery (New Castle, DE). Approximately, $10 \mathrm{mg}$ of the sample was heated from 50 to $600^{\circ} \mathrm{C}$ at a heating rate of $10^{\circ} \mathrm{C} / \mathrm{min}$ under an inert atmosphere $\left(\mathrm{N}_{2}\right)$ at a flow rate of $60 \mathrm{~mL} / \mathrm{min}$. A differential scanning calorimetry (DSC) analysis was performed on a TA Instruments model Discovery (New Castle, DE) under nitrogen atmosphere. Between 5 and $10 \mathrm{mg}$ of the sample was heated from the room temperature $\left(25^{\circ} \mathrm{C}\right)$ to $200^{\circ} \mathrm{C}$, at $10^{\circ} \mathrm{C} / \mathrm{min}$. From the thermograms of the PLA-PNSP biocomposites, the thermal parameters measured were the glass transition temperature $(\mathrm{Tg})$, specific heat change $(\Delta C p)$, enthalpies of melting $(\Delta H \mathrm{H})$ and crystallization just before melting $(\Delta H c)$, the temperatures of crystallization $(T c)$, and melting $(T m)$.

2.9. Morphological Analysis. The surface morphology of the samples was observed using an AmScope model WD165 stereoscope (USA). The images of the samples were captured using magnifications of $1.5 \mathrm{x}$ and $2.5 \mathrm{x}$ of the optical lens. In order to observe the surface morphology of the samples fractured cryogenically, scanning electron microscopy (SEM) with a Philips model XL30 ESEM-FEG (Hillsboro, OR) was carried out. The analysis was conducted in samples coated with a thin layer of Au-Pd plasma produced by a sputter coater (Quorum model QI5OR-ES, Sussex, UK) prior to scanning.

2.10. Statistical Analysis. The experimental data obtained were statistically analyzed by means of a one-way analysis of variance (ANOVA) using NCSS 2007 edition by NCSS LLC (Kaysville, UT). The significance of each property mean was determined $(p<0.05)$ in order to evaluate the effect of the PNSP content (untreated and defatted) on the color, thermal, optical, and mechanical properties of the biocomposites.

\section{Results and Discussions}

3.1. Apparent Color of the Biocomposites. It is important to note that color is an attribute of the commercial composites and biocomposites. The PLA matrix is transparent and uncolored; therefore, the addition of PNSP in the polymeric matrix turned the color of the biocomposite to brown and its shade varied with the PNSP content. Table 1 shows the values of the color parameters, such as luminosity $\left(L^{*}\right)$, chroma $\left(C^{*}\right)$, hue angle or saturation angle $\left(h^{\circ}\right)$, and the color difference $(\Delta E)$ calculated by (1) to (3). The results indicate that as the content of the PNSP increases, the $L^{*}$ and $h^{\circ}$ values decrease; this behavior was observed in both treatments. In addition, the PLA matrix showed the highest $L^{*}$ value, and the biocomposites formulated with $7.5 \% \mathrm{wt}$. PNSP showed lower values of this parameter. The reduction of the $L^{*}$ values is attributed to the close vicinity of the PNSP filler in the PLA matrix. A similar behavior was reported in the PLA-seaweed waste biocomposites [14]. The $C^{*}$ values calculated by (1) are reflecting color purity or saturation. The results from this parameter indicate that the addition of the PNSP increases the color saturation of the biocomposite and significant differences $(p<0.05)$ were found among the formulations. In contrast, the $h^{\circ}$ values showed a significant 
TABLE 1: Color parameters of the PLA-PNSP biocomposites*.

\begin{tabular}{|c|c|c|c|c|c|}
\hline Sample & $\begin{array}{l}\text { PNSP content } \\
\text { (\% wt.) }\end{array}$ & $L^{*}$ & $C^{*}$ & $h^{\circ}$ & $\Delta E$ \\
\hline Neat PLA & $0 \%$ & $88.0 \pm 0.4^{\mathrm{a}}$ & $1.02 \pm 0.1^{c}$ & $317.09 \pm 4.8^{\mathrm{a}}$ & - \\
\hline \multirow{2}{*}{ PNSP defatted } & $5 \%$ & $48.7 \pm 7.4^{\mathrm{b}}$ & $8.173 \pm 0.9^{b}$ & $47.89 \pm 4.3^{\mathrm{b}}$ & $111.9 \pm 18.3^{\mathrm{b}}$ \\
\hline & $7.5 \%$ & $42.6 \pm 0.8^{b c}$ & $11.11 \pm 1.7^{\mathrm{a}, \mathrm{b}}$ & $42.89 \pm 0.5^{\mathrm{b}}$ & $180.4 \pm 39.4^{\mathrm{a}}$ \\
\hline \multirow{2}{*}{ PNSP untreated } & $5 \%$ & $44.8 \pm 1.7^{\mathrm{b}}$ & $14.59 \pm 2.3^{\mathrm{a}}$ & $48.95 \pm 2.3^{\mathrm{b}}$ & $259.6 \pm 71.0^{\mathrm{a}}$ \\
\hline & $7.5 \%$ & $36.2 \pm 3.3^{c}$ & $12.40 \pm 1.1^{\mathrm{a}}$ & $48.32 \pm 7.5^{\mathrm{b}}$ & $200.2 \pm 28.0^{\mathrm{a}}$ \\
\hline
\end{tabular}

${ }^{*}$ Columns with the same letter for each treatment indicate that there is no significant difference $(p<0.05)$ between the samples according to Tukey-Kramer method. Each value is mean \pm standard deviation.

change $(p<0.05)$ in the color of neat PLA and PLA-PNSP biocomposites. $h^{\circ}$ is an important parameter of the color analysis that indicates the position of the color of the sample into the color sphere. The biocomposites showed an $h^{\circ}$ range within the 0 to $90^{\circ}$ region, which means that a reddish yellow color was observed in these formulations. This result agrees with the visible observation of the samples.

The $\Delta E$ values between the formulation $5 \%$ wt., the defatted PNSP formulation, and other formulations showed a significant difference $(p<0.05)$. This color difference between the biocomposites is attributed to factors such as the drying process of the PNSP, filler packaging and content, and dispersion into the PLA matrix [14]. Moreover, similar results were reported by Tisserat et al. [22] using wood particles in order to produce biocomposites by means of an extrusion process. The change in the wood color was attributed to the thermal interactions of the molecules that make up the timber. Also, the authors mentioned that the size and homogenization of the filler particles within the polymer matrix are crucial factors in the color change of the PLAPaulownia wood composites.

3.2. Identification of the Functional Group. The FTIR spectra shown in Figure 1 reveal similar signals for both the neat PLA and the PLA-PNSP biocomposites, regardless of the used treatment, differing only in the signals intensity. MaderaSantana et al. [14] proposed that this is because of the fact that the PLA completely coated the particles of the pecan nutshell and the IR beam only detects signals from the PLA matrix. Nevertheless, the FTIR analysis allowed us to identify that some functional groups showed displacements in their signals due to the interaction between the PLA and the pecan nutshell particles. The absorbance peaks observed are 2998 and $2945 \mathrm{~cm}^{-1}$; they are assigned to the asymmetric $\left(v_{\text {as }}\right)$ and symmetric $\left(v_{\mathrm{s}}\right)$ stretching vibration of $\mathrm{CH}_{3}$ [10]. The signal at $1750 \mathrm{~cm}^{-1}$ corresponds to the stretching region of the carbonyl groups $(\mathrm{C}=\mathrm{O})$, which is characteristic of ester [14]. Other signals in the range of $1500-1300 \mathrm{~cm}^{-1}$ are observed in Figure 1; they are attributed to the symmetric and asymmetric deformational vibration of $\mathrm{C}-\mathrm{H}$ in $\mathrm{CH}_{2}\left(1380\right.$ and $\left.1360 \mathrm{~cm}^{-1}\right)$ and the bending deformation of $\mathrm{CH}_{3}\left(1452 \mathrm{~cm}^{-1}\right)[10,14,23]$. The band registered at $1183 \mathrm{~cm}^{-1}$ is a characteristic signal of the ester groups $(\mathrm{O}-\mathrm{C}=\mathrm{O})$. The intensity of this signal shows a decrease attributed to the PNSP addition. The signals situated at $1215,1128,1084$, and $1045 \mathrm{~cm}^{-1}$ are attributed to

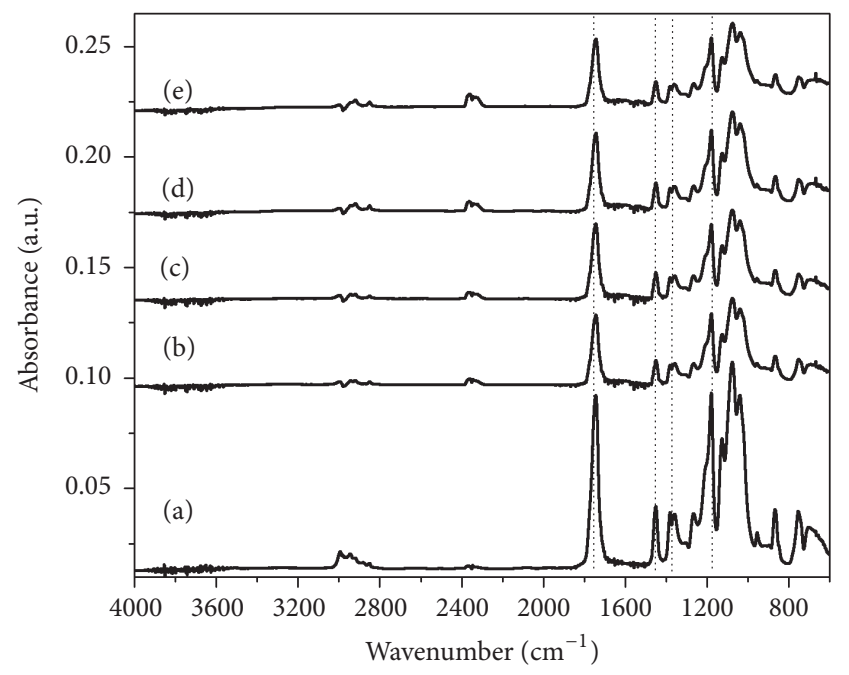

FIGURE 1: FTIR spectra of PLA-PNSP biocomposites: (a) neat PLA, (b) $5 \%$ wt. PNSP defatted, (c) $7.5 \%$ wt. PNSP defatted, (d) $5 \%$ wt. PNSP untreated, and (e) 7.5\% wt. PNSP untreated.

the anhydrides $(\mathrm{C}-\mathrm{CO}-\mathrm{O}-\mathrm{CO}-\mathrm{C})$ valence vibration and the $\mathrm{O}-\mathrm{C}$ stretching vibration from carboxyl [10, 14], and these signals do not change in position in all the spectra.

3.3. Water Absorption. The water absorption of the biocomposites is a key parameter because their possible applications require materials with low absorption values. The biocomposites formulated with untreated PNSP showed higher water absorption, in comparison with the biocomposites with defatted PNSP. This is expected because the PNSP with the defatted treatment shows a lack of tannins (polyphenols) and low molecular lignin that could increase the water absorption of the composites. The results obtained in the biocomposites formulated in this work are presented in Figure 2. The results are consistent with reports from the literature, where polar lignocellulosic fibers show a greater tendency to absorb water, compared to the control samples $[24,25]$. In this case, hydrophilicity is a main feature of the nutshell due to its content of the hydroxyl groups from lignin [26]. Spiridon et al., reported that the lower resistance of the composites to water absorption is attributed to weak interfacial bonding between the filler and the matrix [27] 
TABLE 2: Mechanical parameters from tensile tests of the PLA-PNSP biocomposites* .

\begin{tabular}{lcccc}
\hline Sample & $\begin{array}{c}\text { PNSP content } \\
(\% \text { wt. })\end{array}$ & $\begin{array}{c}\text { Tensile strength } \\
(\mathrm{MPa})\end{array}$ & $\begin{array}{c}\text { Elongation at break } \\
(\%)\end{array}$ & $\begin{array}{c}\text { Tensile modulus } \\
(\mathrm{MPa})\end{array}$ \\
\hline Neat PLA & 0 & $47.3 \pm 2.5^{\mathrm{a}}$ & $43.2 \pm 2.3^{\mathrm{a}}$ & $1902 \pm 206^{\mathrm{a}}$ \\
PNSP defatted & 5 & $32.7 \pm 2.9^{\mathrm{b}}$ & $3.2 \pm 0.8^{\mathrm{b}}$ & $1.1 \pm 0.5^{\mathrm{b}}$ \\
& 7.5 & $38.7 \pm 3.6^{\mathrm{dc}}$ & $4.7 \pm 1.3^{\mathrm{b}}$ & $2108 \pm 132^{\mathrm{a}}$ \\
PNSP untreated & 5 & $41.5 \pm 3.2^{\mathrm{c}}$ & $5.2 \pm 1.3^{\mathrm{b}}$ & $1940 \pm 210^{\mathrm{a}}$ \\
& 7.5 & $31.4 \pm 1.9^{\mathrm{b}}$ & $1504 \pm 228^{\mathrm{b}}$ \\
\hline
\end{tabular}

${ }^{*}$ Columns with the same letter for each treatment indicate that there is no significant difference $(p \leq 0.05)$ between the samples according to Tukey-Kramer method. Each value is mean \pm standard deviation.

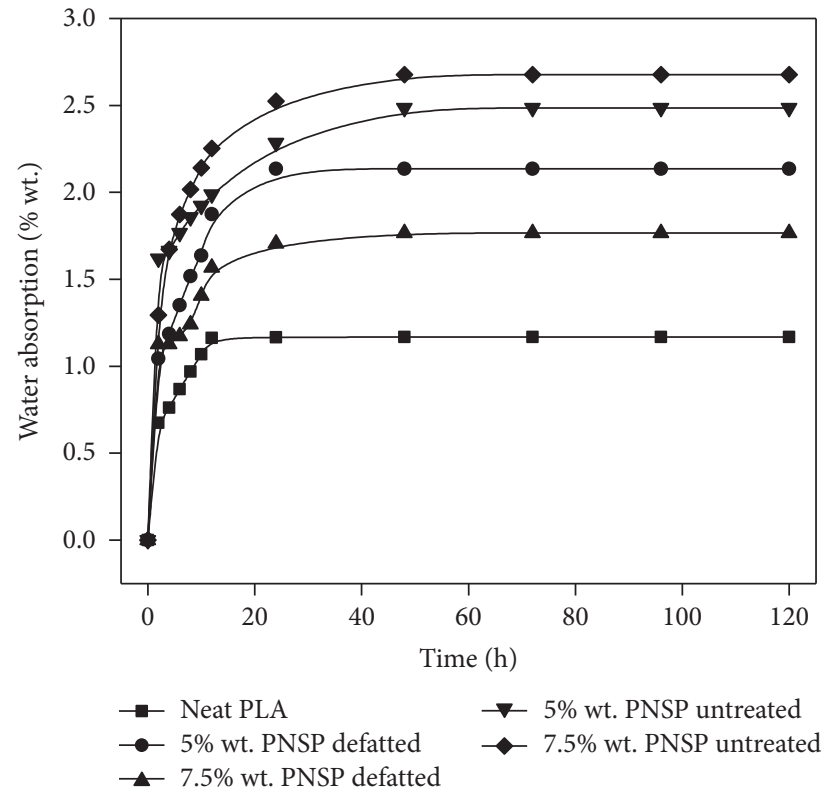

FIgURE 2: Water absorption of neat PLA and PLA-PNSP biocomposites.

These data can be correlated with the mechanical properties of the biocomposites, as it will be discussed later.

3.4. Density. The density values of the biocomposites formulated with PNSP and PLA are shown in Figure 3. It is observed that the density of the neat PLA matrix was significantly lower than for other samples $(p<0.05)$. Also, it is observed that the average density decreased slightly in line with the increase of the pecan shell content in the biocomposites with defatted PNSP. However, this difference was not significant $(p>0.05)$. Alternatively, the density values are higher as the content of the untreated PNSP increases. This difference was not significant either $(p>0.05)$. Usually, during the incorporation of the biofillers into a polymer matrix, air and volatiles may be trapped in the composite, as microvoids, and thus they could affect the physicochemical properties in the biocomposites. In this way, the drying process of raw materials plays an important role in the fabrication of the biocomposites, and the density parameter is essential for their possible applications $[22,28]$.

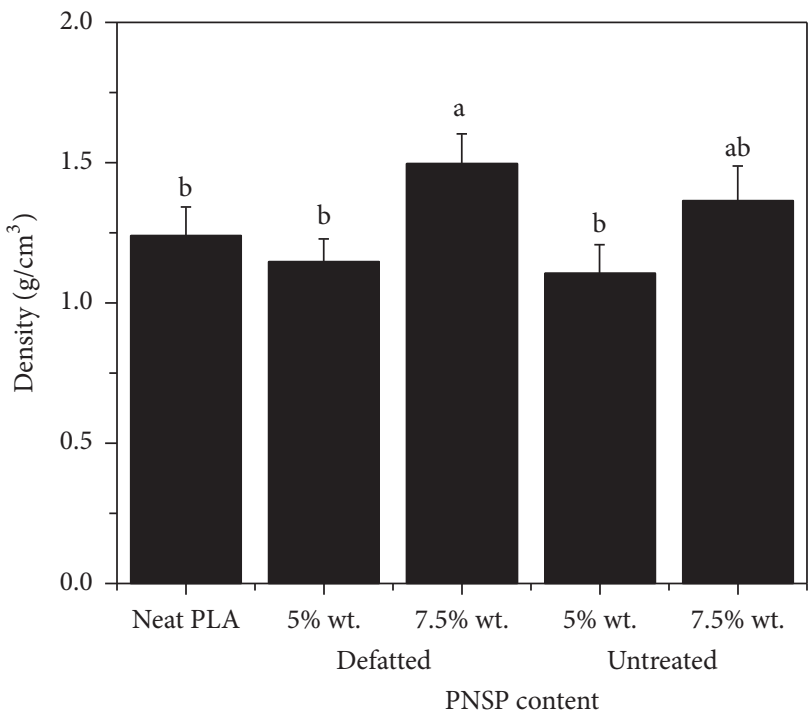

Figure 3: Density values of neat PLA and PLA-PNSP biocomposites.

3.5. Mechanical Properties. Table 2 shows the mechanical parameters calculated from the results of the tensile tests performed on the PLA-PNSP biocomposites. The incorporation of the PNSP into the PLA produced a decrease in tensile strength, the biocomposites formulated with defatted PNSP $(5 \%)$ and untreated PNSP (7.5\%) having the lowest tensile strength values. No statistical significant difference $(p>0.05)$ was found between these formulations. However, the other formulations with the treatments showed an improvement of this property, but they did not reach the tensile strength of the PLA matrix (47.3 MPa). The decrement of the tensile strength in the biocomposites is attributed to factors, such as poor wettability, dispersion, and filler-matrix adhesion. Moreover, another factor responsible for the decrease in strength is related to the differences in polar properties between the nonpolar PLA and the polar filler. The decrease in the maximum stress values in tension agrees with the results from other authors $[4,27,29]$. The elongation at break of the PLA-PNSP biocomposites is shown in Table 2. The results show that the elongation at break of the biocomposites was significantly different $(p<0.05)$ compared to the neat PLA. The incorporation of the PNSP produced a significant decrease $(p<0.05)$ of the elongation at break, although 


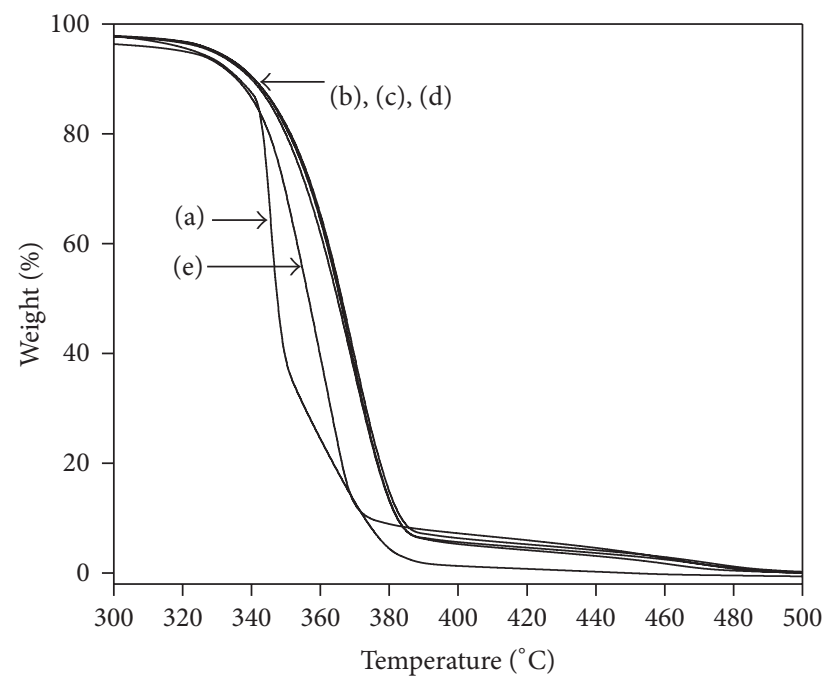

FIGURE 4: TGA thermograms of the PLA-PNSP biocomposites: (a) neat PLA, (b) 5\% wt. PNSP defatted, (c) 7.5\% wt. PNSP defatted, (d) $5 \%$ wt. PNSP untreated, and (e) $7.5 \%$ wt. PNSP untreated.

all the formulations of the biocomposites did not show significant changes in this parameter. The decrease in the elongation at break is expected considering that the addition of PNSP reduces the chain mobility of the PLA matrix and increases the stiffness of the biocomposite. A similar behavior has been observed on the elongation at break in thermoplastic biocomposites $[4,7,14,22]$.

The tensile modulus values of the PLA-PNSP biocomposites are shown in Table 2. The average tensile modulus of the biocomposites with 7.5\% defatted PNSP and 5\% untreated PNSP was slightly higher in comparison with the neat PLA matrix. The other formulated biocomposites show a significant decrease $(p<0.05)$ in this parameter. Some authors have reported that fillers added to thermoplastic matrices restrict the movement of the chains of the polymeric material (reducing ductility), thereby increasing the modulus of elasticity [7]. However, the biocomposites of the neat PLA mixed with organic fillers without coupling agents had shown a similar tendency in the mechanical parameters $[13,14]$.

3.6. Thermal Analysis. A thermal analysis is defined as a group of techniques in which a property of the sample is monitored against time or temperature in a specified atmosphere [30]. The thermogravimetric analyzer (TGA) was used in order to determine the thermal stability of the neat PLA and PLA-PNSP biocomposites, with a particular interest in the measurement of weight as a function of temperature. In Figure 4, the TGA thermograms of the PLA and the biocomposites in a temperature range of $300-500^{\circ} \mathrm{C}$ are presented. In general, the thermograms of the biocomposites have shown similarities between them and the weight loss in all samples occurred in a single step. These thermograms showed a thermal stability up to $300^{\circ} \mathrm{C}$ and, shortly after, this temperature began an inflection, which represented the thermal degradation of the components of the biocomposite and finished at $395^{\circ} \mathrm{C}$. Moreover, slight shifts in the thermogram

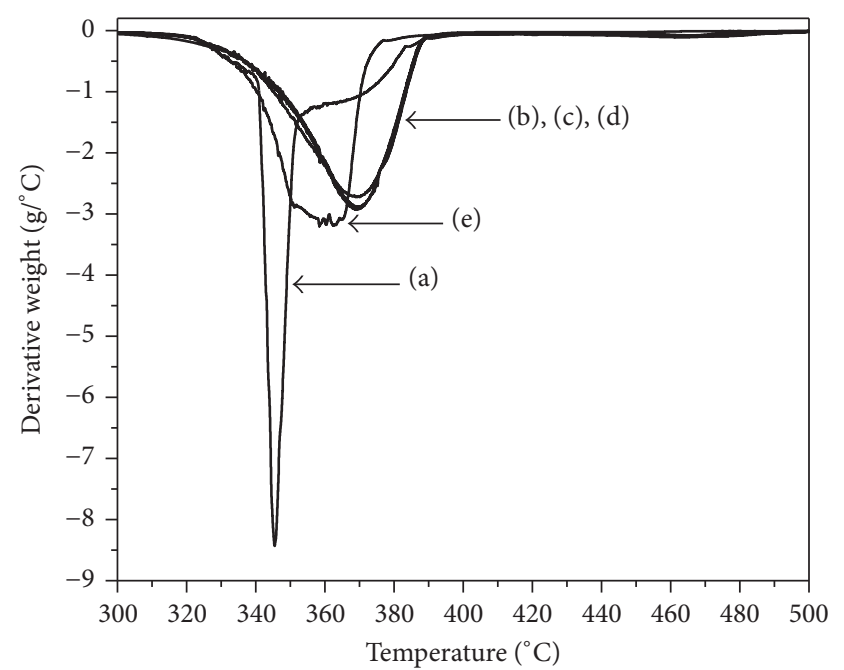

FIgURE 5: DTGA thermograms of the PLA-PNSP biocomposites: (a) neat PLA, (b) 5\% wt. PNSP defatted, (c) 7.5\% wt. PNSP defatted, (d) $5 \%$ wt. PNSP untreated, and (e) $7.5 \%$ wt. PNSP untreated.

formulations containing PNSP over the PLA matrix are observed. The thermograms of the biocomposites with a defatted PNSP of 5\% and 7.5\% and an untreated PNSP of 5\% show a similar behavior. Furthermore, these samples showed an improvement in the thermal stability and a displacement of the degradation temperature to a higher value, in comparison with the neat PLA. Subsequently, in Figure 5, the first derivatives of the TGA thermograms (DTGA) of the biocomposites are shown for their different concentrations and treatments. The intervals of the decomposition temperature of the neat PLA and the biocomposites formulated are between 310 and $395^{\circ} \mathrm{C}$. In addition, the concentrations of the PNSP with $5 \%$ and $7.5 \%$ untreated and the formulation of 5\% PNSP defatted have the same decomposition temperature $\left(372^{\circ} \mathrm{C}\right)$. In contrast, neat PLA and the biocomposite with $7.5 \mathrm{wt} . \%$ untreated PNSP showed decomposition temperatures of 343 and $361^{\circ} \mathrm{C}$, respectively. The increase in the thermal stability of the PLA-PNSP biocomposites could be attributed to the char formation and it acts as a protective barrier in the PLA matrix from the thermal decomposition [4]. Our results agree with the results reported by Madera-Santana et al. [14], where these authors reported a single degradation step in the PLAseaweed waste biocomposites through the temperature runs, as well as a slight increase in the decomposition temperature of the biocomposites.

The DSC is used in order to identify and quantify various physicochemical parameters of the polymers, such as the glass transition temperature and crystallization temperature. In Table 3, the thermal parameters calculated from the first run of this analysis are shown and it is noted that the glass transition temperature $(\mathrm{Tg})$ of the biocomposites containing PNSP was slightly lower than the PLA matrix; that is, as the content of the PNSP increased, the $\mathrm{Tg}$ value decreased, regardless of the treatment type. A similar behavior was observed in the crystallization temperature $(T c)$; as the content of the PNSP was increased, this parameter decreased. 
TABLE 3: Thermal data measurements obtained by differential scanning calorimetry of the PLA-PNSP biocomposites.

\begin{tabular}{lccccccc}
\hline Sample & $\begin{array}{c}\text { PNSP content } \\
\text { (\% wt. })\end{array}$ & $\begin{array}{c}\mathrm{Tg} \\
\left({ }^{\circ} \mathrm{C}\right)\end{array}$ & $\begin{array}{c}\mathrm{Tc} \\
\left({ }^{\circ} \mathrm{C}\right)\end{array}$ & $\begin{array}{c}\Delta H c \\
(\mathrm{~J} / \mathrm{g})\end{array}$ & $\begin{array}{c}\mathrm{Tm}^{1} \\
\left({ }^{\circ} \mathrm{C}\right)\end{array}$ & $\begin{array}{c}\mathrm{Tm}{ }^{2} \\
\left({ }^{\circ} \mathrm{C}\right)\end{array}$ & $\begin{array}{c}\Delta H m \\
(\mathrm{~J} / \mathrm{g})\end{array}$ \\
\hline Neat PLA & $0 \%$ & 62.5 & 111.7 & 24.3 & 149.5 & 154.9 & 26.9 \\
PNSP defatted & $5 \%$ & 57.9 & 104.6 & 26.9 & 148.1 & 156.9 & 27.9 \\
& $7.5 \%$ & 58.4 & 106.4 & 25.7 & 149.0 & 156.4 & 28.9 \\
PNSP untreated & $5 \%$ & 60.1 & 106.2 & 27.9 & 156.0 & 156.0 & 25.6 \\
& $7.5 \%$ & 59.8 & 107.2 & 25.9 & 148.3 & 155.9 \\
\hline
\end{tabular}

$\mathrm{Tg}$, glass transition temperature; $T c$, crystallization temperature; $\Delta H c$, crystallization enthalpy; $\mathrm{Tm}^{1}$, first melting temperature signal; $\mathrm{Tm}^{2}$, second melting temperature signal; $\Delta H m$, melting enthalpy.

However, the $T c$ values of the biocomposites with untreated PNSP showed the higher values. For the crystallization enthalpy $(\Delta H c)$, the PLA matrix showed a lower value in comparison with the biocomposites. The incorporation of PNSP in the PLA matrix increased the $\Delta H c$ value, indicating that the PNSP acts as a nucleating agent of crystallization for the PLA matrix. From the results of the melting temperature $(\mathrm{Tm})$ in the thermograms (data not shown), a double melting peak was observed, which is why $T m^{1}$ and $T m^{2}$ are reported in Table 3, respectively. The enthalpy of the melting $(\Delta \mathrm{Hm})$ values of the neat PLA is lower, compared with the samples containing the PNSP for both treatments. The highest $\Delta H \mathrm{~m}$ was observed in the biocomposite with $7.5 \%$ wt. PNSP defatted.

According to Fortunati et al., a decrease in the $\mathrm{Tg}$ values is related to the low miscibility of the polymer mixture [31]. Mathew et al. reported that the composite materials formulated with cellulose fibers exhibit an increase in $\mathrm{Tg}$ compared to the PLA matrix [32]. In contrast, some authors have reported that biocomposites based on the PLA show a decrease of $\mathrm{Tg}$; they attributed that the inclusion of biofillers produces a reduction on the PLA chain mobility [33]. The cold crystallization temperature $(T c)$ is influenced by the filler, regardless of type and content, and is responsible for a significant reduction of this temperature [11], as it can be observed in the $T c$ values of Table 3. Finally, the double peak of the melting temperature of the neat PLA and PLAPNSP biocomposite is attributed to the rearrangement of the lamellar fraction observed during the PLA crystallization and melting of small crystals $[12,23]$.

3.7. Dynamic Mechanical Analysis. The dynamic mechanical properties of the biocomposites in terms of the storage modulus $\left(E^{\prime}\right)$ and the loss modulus $\left(E^{\prime \prime}\right)$ are shown in Figures 6 and 7 , respectively. $E^{\prime}$ is helpful in surveying the molecular base of the mechanical properties of the biocomposites since it is sensible to basic changes, for example, structural and interfacial bonding between the fiber and particle-matrix. It can be observed in Figure 6 that the change in the storage modulus values depends on the filler content and temperature. The biocomposite with 7.5\% wt. defatted PNSP showed the highest $E^{\prime}$, that is, being the most rigid biocomposite, followed by the biocomposite of the same PNSP concentration, but with different treatment. The increase of the PNSP content has decreased $E^{\prime}$ of the biocomposites and this effect is more pronounced in formulations with $5 \% \mathrm{wt}$. PNSP. As indicated in Figure 6, the $E^{\prime}$ values decreased in line with the increasing PNSP content, which is attributed to the agglomeration, dispersion, and distribution of the PNSP into the matrix. It caused poor interfacial adhesion, which diminished the interfacial bonding strength. $E^{\prime}$ of the neat PLA dropped at around $57^{\circ} \mathrm{C}$, but the PLA-PNSP biocomposites were thermally more stable $\left(>65^{\circ} \mathrm{C}\right)$ in comparison with the neat PLA. The exception was the formulation with $5 \%$ wt. defatted PNSP. Sperling indicated that changes in the amorphous-crystalline interface, concentration, particle size filler, and the area of the loading surface are factors that can affect $E^{\prime}$ of the biocomposites [33].

Figure 7 shows $E^{\prime \prime}$ as a function of temperature. The maximum value of $E^{\prime \prime}$ was observed for the biocomposite with $7.5 \%$ wt. defatted PNSP and it was higher than the neat PLA. The $E^{\prime \prime}$ peak of the biocomposites compared to the neat PLA showed a decrease as a result of the PNSP addition. It is the particle rigidity of the PNSP that interrupts the movement of the PLA chains and contributes to greater mechanical losses, so this large scale movement elongates the glass transition range [34].

Generally, $\tan \delta$ is the ratio of the storage and the loss modulus; it indicates a relationship between loss and the recoverable energy [34]. In Figure 8, the behavior of $\tan \delta$ versus temperature is shown for the neat PLA and the PLA-PNSP biocomposites. This figure shows that the signals appear in different temperatures and that the peak intensities were higher than those obtained for the neat PLA and PLAPNSP biocomposites. All the biocomposite formulations showed a $\tan \delta$ peak at higher temperatures $\left(>50^{\circ} \mathrm{C}\right)$, with the biocomposites formulated with defatted PNSP showing temperatures above $65^{\circ} \mathrm{C}$. This result is indicating that the defatted treatment in the PNSP produced a higher restriction in the molecular mobility of the biocomposites. Similar results were reported by Gregorova et al. for the PLA-wood flour composites [21]. Moreover, different investigations of the biocomposites have discussed the effect of rigid fillers in polymeric matrices, which report that the fillers contribute to higher mechanical and thermal losses in the biocomposites $[21,35]$.

3.8. Surface Morphology. The physical properties of the composites are influenced by their morphology. Therefore, the microscopic study of these properties is useful for 


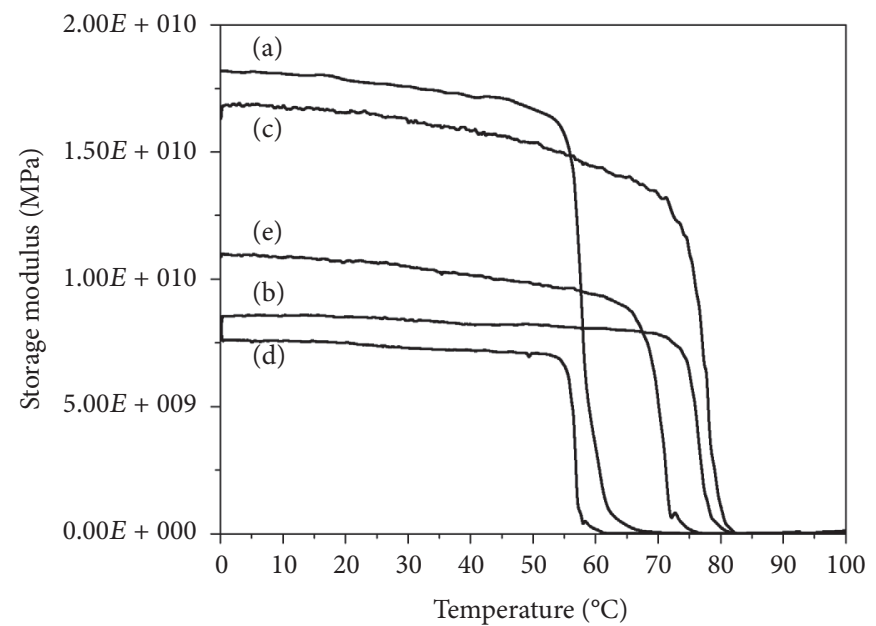

Figure 6: Storage modulus of the PLA-PNSP biocomposites: (a) neat PLA, (b) 5\% wt. PNSP defatted, (c) 7.5\% wt. PNSP defatted, (d) 5\% wt. PNSP untreated, and (e) $7.5 \%$ wt. PNSP untreated.

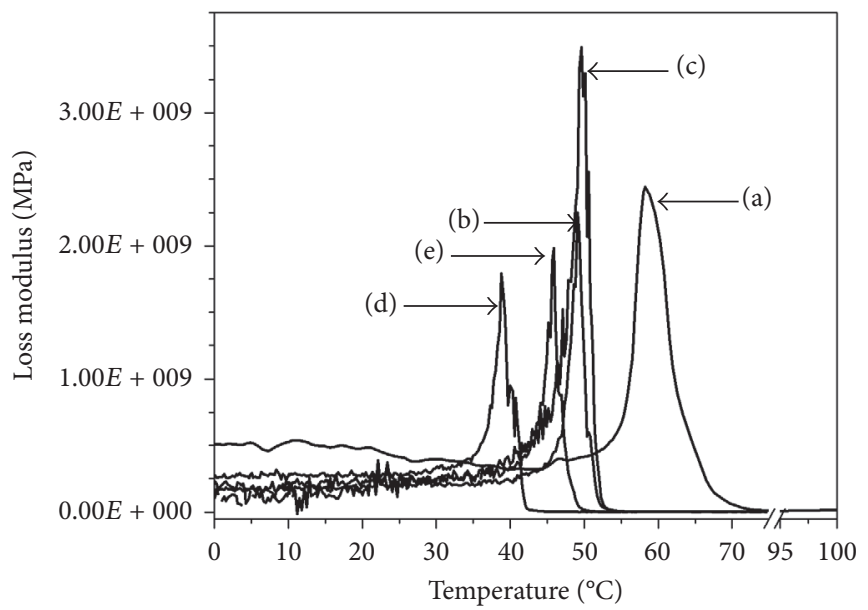

Figure 7: Loss modulus of the PLA-PNSP biocomposites: (a) neat PLA, (b) 5\% wt. PNSP defatted, (c) 7.5\% wt. PNSP defatted, (d) 5\% wt. PNSP untreated, and (e) $7.5 \%$ wt. PNSP untreated.

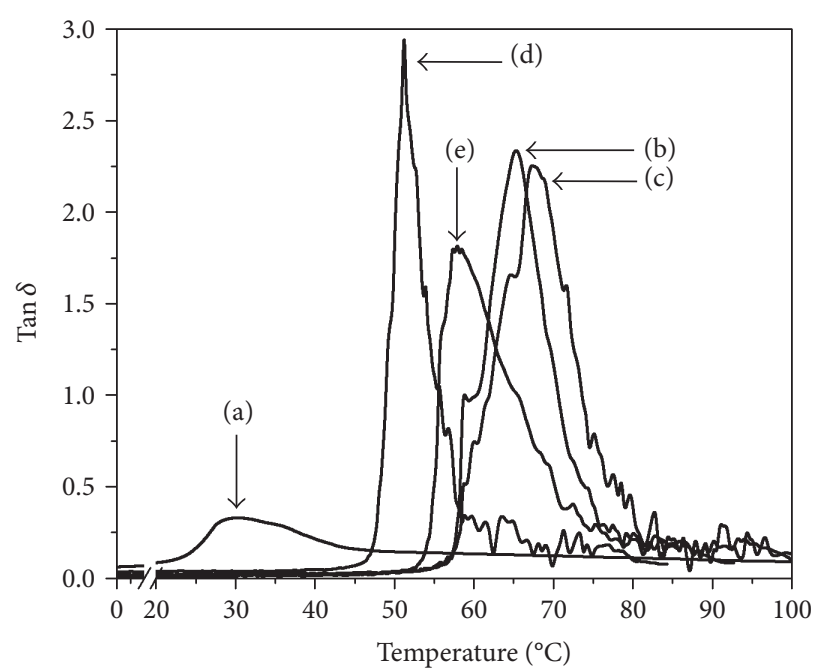

Figure 8: $\tan \delta$ of the PLA-PNSP biocomposites: (a) neat PLA, (b) 5\% wt. PNSP defatted, (c) 7.5\% wt. PNSP defatted, (d) 5\% wt. PNSP untreated, and (e) 7.5\% wt. PNSP untreated. 


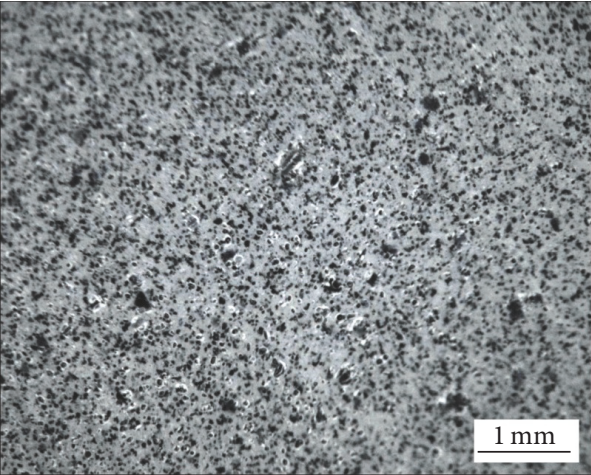

(a)

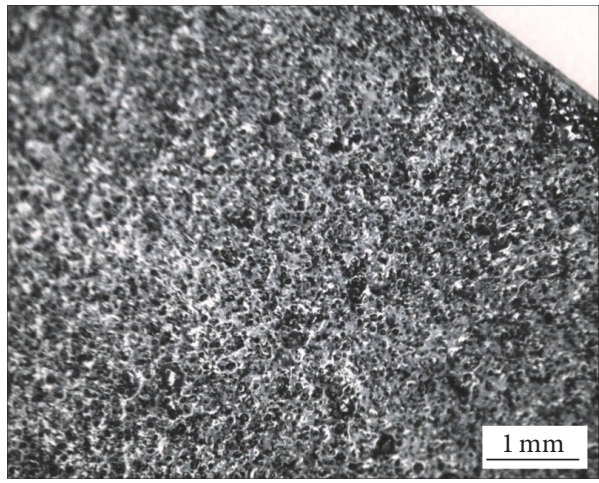

(c)

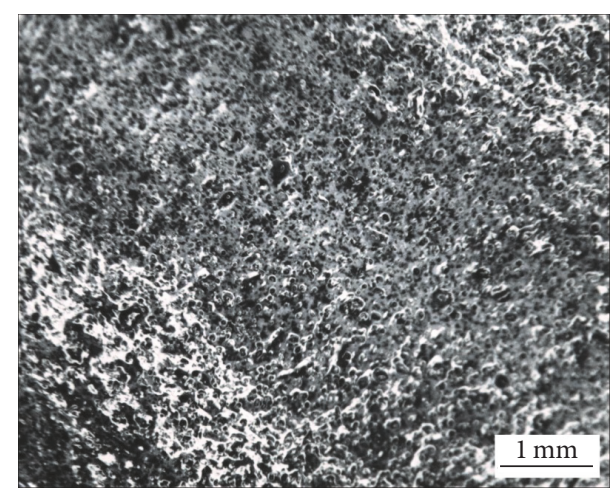

(b)

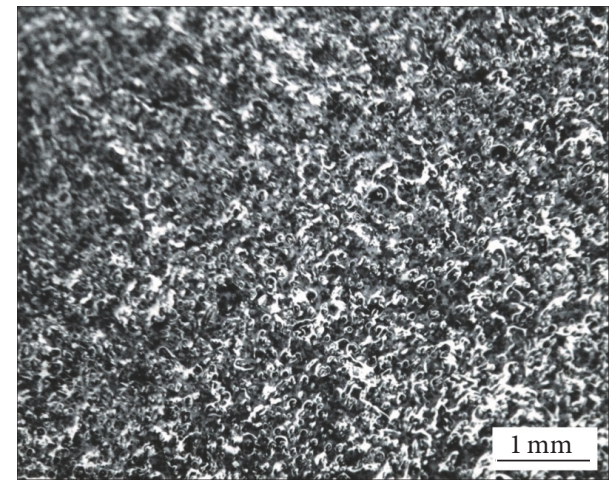

(d)

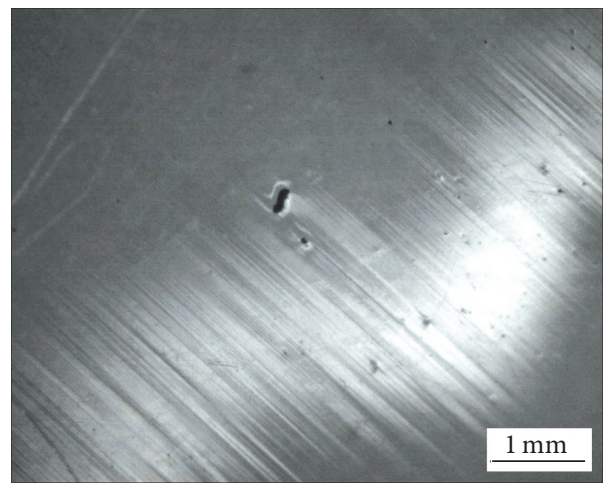

(e)

FIGURE 9: Morphology of PLA-PNSP biocomposite surfaces at different treatments: (a) 5\% wt. PNSP defatted, (b) 7.5\% wt. PNSP defatted, (c) $5 \%$ wt. PNSP untreated, (d) 7.5\% wt. PNSP untreated, and (e) neat PLA.

understanding the behavior of these materials. The images of the surface morphology of the neat PLA and PLA-PNSP biocomposites obtained from a stereoscopic microscope at a magnification of 2.5x are presented in Figures 9(a)-9(e). In general terms, the PNSP showed a homogeneous distribution and fine dispersion in the PLA matrix. Biocomposites with a content of 5\% wt. PNSP (Figures 9(a) and 9(c)) had small clumps of this material, while the biocomposites with the highest content of PNSP (7.5\% wt.) (Figures 9(b) and $9(d)$ ) showed fewer dust-free spaces and a certain degree of porosity. This is because the content of the PNSP of this formulation is too high and thus the particles are on the surface of the biocomposite. Figure 9(e) corresponds to the surface of the PLA matrix; the parallel lines on the surface are produced by the extruder die. Our results agree with the morphological studies of Mathew et al., in which the authors mentioned that the tendency of the PLA to involve the fillers used in biocomposites is attributed to its low melt viscosity [32]. Based on the above, it can be said that, in the case of biocomposites, as those that have been developed in this work, the surface topography reveals a certain cohesion degree of the components, which depends on the PSNP content. This parameter plays a significant role developing the reinforcing effect of the PNSP in the PLA matrix. 


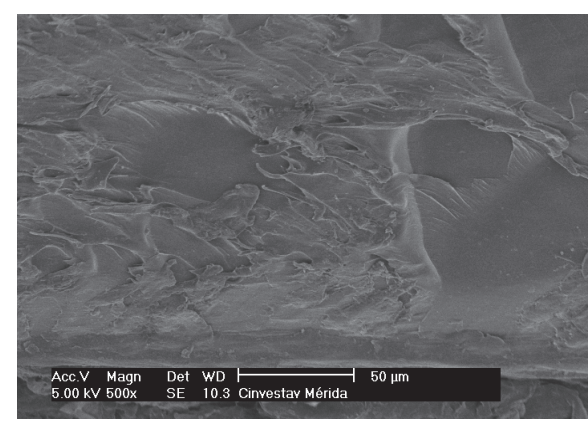

(a)

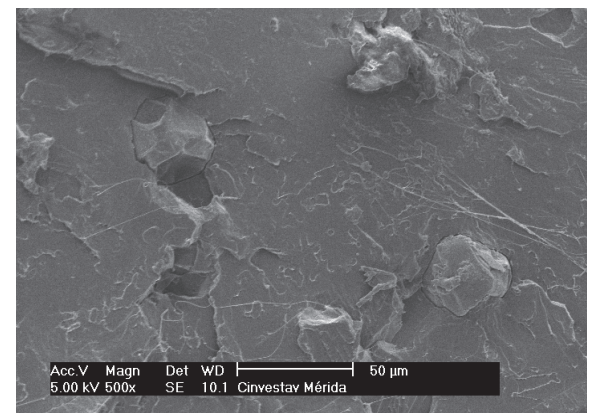

(c)

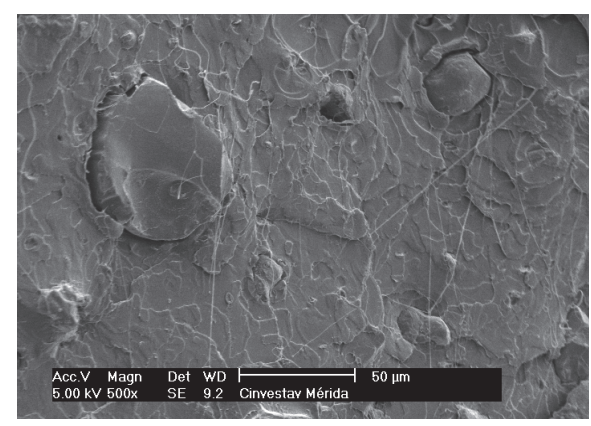

(b)

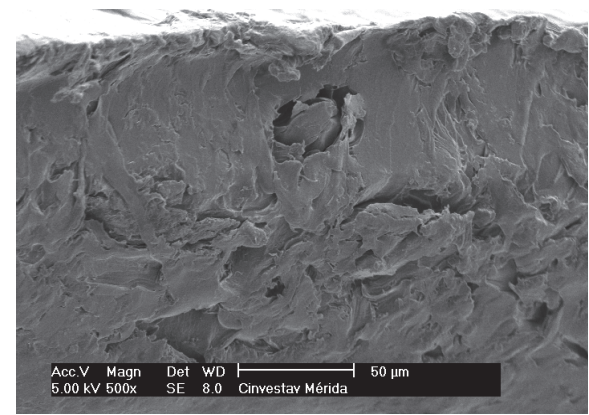

(d)

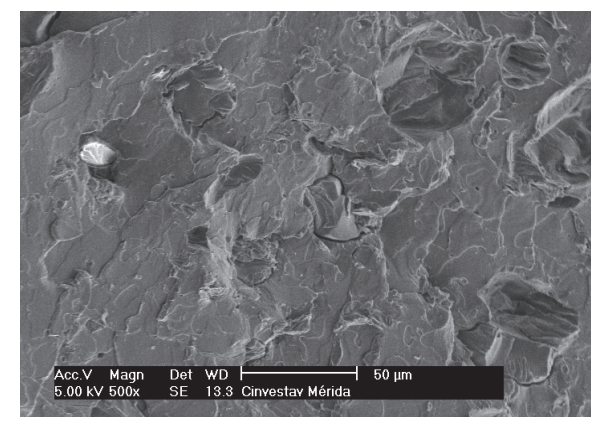

(e)

Figure 10: Morphology of fracture surface of PLA-PNSP biocomposites at 500x magnification: (a) neat PLA, (b) 5\% wt. PNSP defatted, (c) 5\% wt. PNSP untreated, (d) 7.5\% wt. PNSP defatted, and (e) 7.5\% wt. PNSP untreated.

The interfacial morphology of the PLA-PNSP biocomposites is shown in Figure 10. The micrographs of the fracture surface of the biocomposites at a magnification of 500x were examined by the SEM. Figure 10(a) shows the micrograph of the fractured surface of the PLA matrix. The behavior observed in this fractured surface shows fragile and ductile performance (matrix tearing of PLA). The biocomposites analyzed showed a homogeneous distribution and good dispersion of the PNSP. Moreover, the interfacial adhesion between the PLA and the filler powder in the biocomposites has shown that certain particles are not detached from the matrix; instead these stay embedded and only had a takeoff.

The surface morphology of the 5 and $7 \%$ wt. defatted PNSP biocomposites (Figures 10(b) and 10(d)) showed rougher areas in comparison with the untreated PNSP biocomposites. Also, the embedded particles presented more defined holes, but the PNSP were not released from the matrix. This can be interpreted as a good interaction between the polymeric matrix and the PNSP. Furthermore, the biocomposites formulated with untreated PNSP are shown in Figures 10(c) and 10(e). These micrographs show few holes where the PNSP was released from the polymeric matrix, meaning that the untreated PNSP does not interact strongly enough. Upon associating the micrographs in Figure 10 with the results of the mechanical analysis (tensile strength), we noted the concordance with the formulation of the $7.5 \%$ wt. defatted PNSP biocomposite. In this way, Mohanty et al. reported that waxy substances contribute to ineffective matrix-filler interactions [29]. Meanwhile, Shah et al. [36] mentioned that the particle size and surface roughness are important for the adhesion of a filler in a polymer matrix. Boontima et al. mentioned that the biocomposites processed from extrusion have a better homogenization of the particles within the PLA, compared to other processing methods [35]. Also, they indicated that the wax and other compounds rich in fatty acids form a thin film on the filler surface. It could 
be occurring between the polymer matrix of the PLA and the untreated PNSP.

\section{Conclusions}

Untreated PLA and PNSP biocomposites, or biocomposites subjected to the defatting process, were prepared by means of extrusion and characterized. The color parameter values of the biocomposites indicate that an increase in the PNSP content produced a reddish yellow color in these formulations. The color difference between the biocomposites is due to the filler content and packaging, dispersion, and drying process. The structural analysis (FTIR) showed that the PLA-PNSP biocomposites did not form new functional groups. The addition of untreated PNSP in the PLA matrix increased the water absorption capacity and improved the thermal stability of the biocomposites. The tensile strength and elongation at break showed a significant decrease in their values when the PNSP was added to the PLA matrix. The morphological analysis showed good dispersion and adhesion of the PNSP, although certain particle agglomerations were observed in the biocomposites.

The release of fat from the PNSP did not affect the physicochemical, mechanical, or thermal characteristics of the biocomposites; it was attributed to the low content of the filler in the PLA matrix. In further research, it would be of interest to use a twin screw extrusion in order to help the dispersion of the PNSP and to determine the properties of the biocomposites with a higher PNSP content into the PLA matrix. Finally, pecan nutshells are an abundant agroindustrial residue in certain regions, where their use may benefit the economic sector and avoid environmental pollution as a sustainable alternative as filler in bioplastic materials in applications, where the cost factor is a concern and reducing certain properties is acceptable without affecting the performance of the material.

\section{Conflicts of Interest}

The authors declare that there are no conflicts of interest regarding the publication of this paper.

\section{Acknowledgments}

D. L. Sánchez-Acosta (CVU: 661403) thanks CONACYT for the scholarship for the master's studies at the University of Sonora. The authors wish to acknowledge Mrs. Ana Ruth Cristobal Ramos and Dora Huerta Quintana, MSc., for their technical support regarding the SEM micrographs. The thermal analysis was conducted in the facilities of LANNBIO at CINVESTAV-Mérida under the projects FOMIX-Yucatán 2008-108160 and CONACYT LAB-2009-01 no. 123913 and CONACYT nos. 188345 and 204822.

\section{References}

[1] K. Fukushima, C. Abbate, D. Tabuani, M. Gennari, and G. Camino, "Biodegradation of poly(lactic acid) and its nanocomposites," Polymer Degradation and Stability, vol. 94, no. 10, pp. 1646-1655, 2009.
[2] D. Ç. Ayfer, K. Hülya, and M. Fatih, "Tea mill waste fibers filled thermoplastic composites: the effects of plastic type and fiber loading," Journal of Reinforced Plastics and Composites, vol. 30, no. 10, pp. 833-844, 2011.

[3] F. Z. El Mechtali, H. Essabir, S. Nekhlaoui et al., "Mechanical and thermal properties of polypropylene reinforced with almond shells particles: impact of chemical treatments," Journal of Bionic Engineering, vol. 12, no. 3, pp. 483-494, 2015.

[4] K. S. Chun, S. Husseinsyah, and H. Osman, "Mechanical and thermal properties of coconut shell powder filled polylactic acid biocomposites: effects of the filler content and silane coupling agent," Journal of Polymer Research, vol. 19, no. 5, pp. 1-8, 2012.

[5] H. Essabir, M. O. Bensalah, D. Rodrigue, R. Bouhfid, and A. El Kacem Qaiss, "Biocomposites based on argan nut shell and a polymer matrix: effect of filler content and coupling agent," Carbohydrate Polymers, vol. 143, no. 14, pp. 70-83, 2016.

[6] I. Naghmouchi, F. X. Espinach, P. Mutjé, and S. Boufi, "Polypropylene composites based on lignocellulosic fillers: how the filler morphology affects the composite properties," Materials and Design, vol. 65, no. 1, pp. 454-461, 2015.

[7] N. Ayrilmis, A. Kaymakci, and F. Ozdemir, "Physical, mechanical, and thermal properties of polypropylene composites filled with walnut shell flour," Journal of Industrial and Engineering Chemistry, vol. 19, no. 3, pp. 908-914, 2013.

[8] I. Leceta, A. Etxabide, S. Cabezudo, K. De La Caba, and P. Guerrero, "Bio-based films prepared with by-products and wastes: environmental assessment," Journal of Cleaner Production, vol. 64, no. 1, pp. 218-227, 2014.

[9] M. Jamshidian, E. A. Tehrany, M. Imran, M. Jacquot, and S. Desobry, "Poly-Lactic Acid: production, applications, nanocomposites, and release studies," Comprehensive reviews in food science and food safety, vol. 9, no. 5, pp. 552-571, 2010.

[10] D. Garlotta, “A literature review of poly(lactic acid)," Journal of Polymers and the Environment, vol. 9, no. 1, pp. 63-84, 2001.

[11] D. Battegazzore, J. Alongi, and A. Frache, "Poly(lactic acid)Based Composites Containing Natural Fillers: Thermal, Mechanical and Barrier Properties," Journal of Polymers and the Environment, vol. 22, no. 1, pp. 88-98, 2014.

[12] M. L. Di Lorenzo and R. Androsch, "Crystallization of Poly(lactic acid)," in Biodegradable Polyesters, S. Fakirov, Ed., Wiley-VCH Verlag GmbH and Co. KGaA, Weinheim, Germany, 2015.

[13] N. Sutivisedsak, H. N. Cheng, C. S. Burks et al., "Use of nutshells as fillers in polymer composites," Journal of Polymers and the Environment, vol. 20, no. 2, pp. 305-314, 2012.

[14] T. J. Madera-Santana, Y. Freile-Pelegrín, J. C. Encinas, C. R. Ríos-Soberanis, and P. Quintana-Owen, "Biocomposites based on poly(lactic acid) and seaweed wastes from agar extraction: evaluation of physicochemical properties," Journal of Applied Polymer Science, vol. 132, no. 31, Article ID 42320, pp. 4232042327, 2015.

[15] F. J. Aranda-García, R. González-Núñez, C. F. Jasso-Gastinel, and E. Mendizábal, "Water absorption and thermomechanical characterization of extruded starch/poly(lactic acid)/agave bagasse fiber bioplastic composites," International Journal of Polymer Science, vol. 2015, Article ID 343294, 7 pages, 2015.

[16] H. Essabir, M. O. Bensalah, D. Rodrigue, R. Bouhfid, and A. Qaiss, "Structural, mechanical and thermal properties of biobased hybrid composites from waste coir residues: Fibers and shell particles," Mechanics of Materials, vol. 93, pp. 134-144, 2016. 
[17] H. Essabir, M. E. Achaby, E. M. Hilali, R. Bouhfid, and A. Qaiss, "Morphological, structural, thermal and tensile properties of high density polyethylene composites reinforced with treated argan nut shell particles," Journal of Bionic Engineering, vol. 12, no. 1, pp. 129-141, 2015.

[18] C. Dong and I. J. Davies, "Flexural properties of macadamia nutshell particle reinforced polyester composites," Composites Part B: Engineering, vol. 43, no. 17, pp. 2751-2756, 2012.

[19] S. Gupta, G. Dangayach, and A. K. Singh, "Key determinants of sustainable product design and manufacturing," Procedia CIRP, vol. 26, no. 2, pp. 99-102, 2015.

[20] B. S. Hayes and L. M. Gammon, "Optical microscopy of fiberreinforced composites," ASM International, 2010.

[21] A. Gregorova, M. Hrabalova, R. Kovalcik, and R. Wimmer, "Surface modification of spruce wood flour and effects on the dynamic fragility of PLA/wood composites," Polymer Engineering and Science, vol. 51, no. 1, pp. 143-150, 2011.

[22] B. Tisserat, N. Joshee, A. K. Mahapatra, G. W. Selling, and V. L. Finkenstadt, "Physical and mechanical properties of extruded poly(lactic acid)-based Paulownia elongata biocomposites," Industrial Crops and Products, vol. 44, no. 1, pp. 88-96, 2013.

[23] F. Carrasco, P. Pagès, J. Gámez-Pérez, O. O. Santana, and M. L. Maspoch, "Processing of poly(lactic acid): Characterization of chemical structure, thermal stability and mechanical properties," Polymer Degradation and Stability, vol. 95, no. 2, pp. 116$125,2010$.

[24] R. Belhassen, S. Boufi, F. Vilaseca et al., "Biocomposites based on Alfa fibers and starch-based biopolymer," Polymers for Advanced Technologies, vol. 20, no. 12, pp. 1068-1075, 2009.

[25] L. Qin, J. Qiu, M. Liu et al., "Mechanical and thermal properties of poly(lactic acid) composites with rice straw fiber modified by poly(butyl acrylate)," Chemical Engineering Journal, vol. 166, no. 2, pp. 772-778, 2011

[26] L. Dolan, R. Matulka, J. Worn, and J. Nizio, "Safety studies conducted on pecan shell fiber, a food ingredient produced from ground pecan shells," Toxicology Reports, vol. 3, no. 1, pp. 87-97, 2016.

[27] I. Spiridon, R. N. Darie-Nita, G. E. Hitruc, J. Ludwiczak, I. A. Cianga Spiridon, and M. Niculaua, "New opportunities to valorize biomass wastes into green materials," Journal of Cleaner Production, vol. 133, no. 81, pp. 235-242, 2016.

[28] V. Nagarajan, A. K. Mohanty, and M. Misra, "Sustainable green composites: value addition to agricultural residues and perennial grasses," ACS Sustainable Chemistry and Engineering, vol. 1, no. 3, pp. 325-333, 2013.

[29] A. Mohanty, M. Misra, and L. Drzal, Natural Fibers, Biopolymers, and Biocomposites, CRC Press, 2005.

[30] M. E. Brown, "Handbook of thermal analysis and calorimetry," in Elsevier Science B. V, vol. 1, 2003.

[31] E. Fortunati, I. Armentano, A. Iannoni, and J. Kenny, "Development and thermal behaviour of ternary PLA matrix composites," Polymer Degradation and Stability, vol. 95, no. 11, pp. 22002206, 2010.

[32] A. P. Mathew, K. Oksman, and M. Sain, "The effect of morphology and chemical characteristics of cellulose reinforcements on the crystallinity of polylactic acid," Journal of Applied Polymer Science, vol. 101, no. 15, pp. 300-310, 2006.

[33] L. H. Sperling, "Glass-rubber transition behavior," in Introduction to Physical Polymer Science, Wiley, 4th edition, 2005.

[34] K. P. Menard, Dynamic Mechanical Analysis: A Practical Introduction, CRC Press, 2008.
[35] B. Boontima, A. Noomhorm, C. Puttanlek, D. Uttapap, and V. Rungsardthong, "Mechanical properties of sugarcane bagasse fiber-reinforced soy based biocomposites," Journal of Polymers and the Environment, vol. 23, no. 1, pp. 97-106, 2015.

[36] B. L. Shah, S. E. Selke, M. B. Walters, and P. A. Heiden, "Effects of wood flour and chitosan on mechanical, chemical, and thermal properties of polylactide," Polymer Composites, vol. 29, no. 8, pp. 655-663, 2008. 

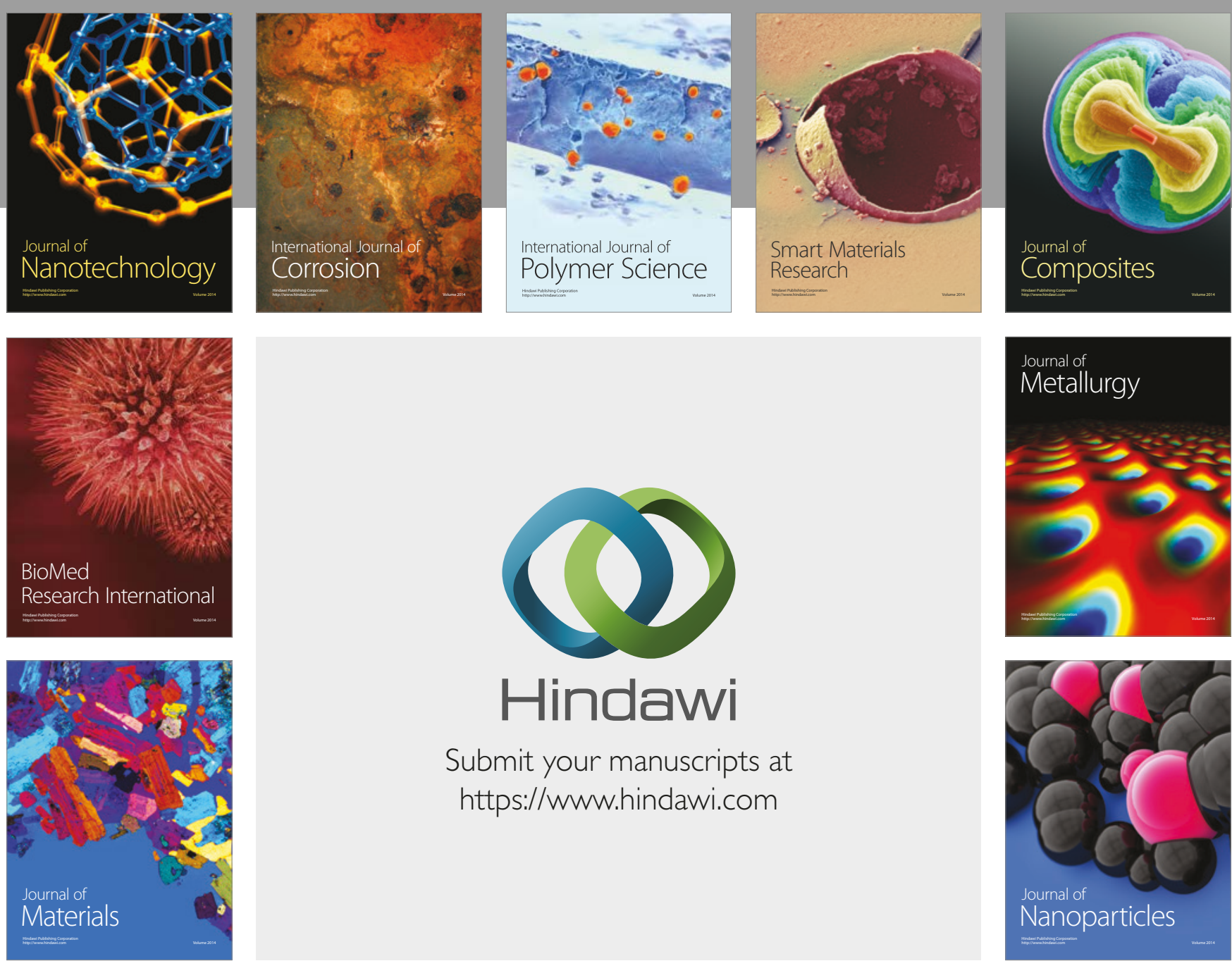

\section{Hindawi}

Submit your manuscripts at

https://www.hindawi.com
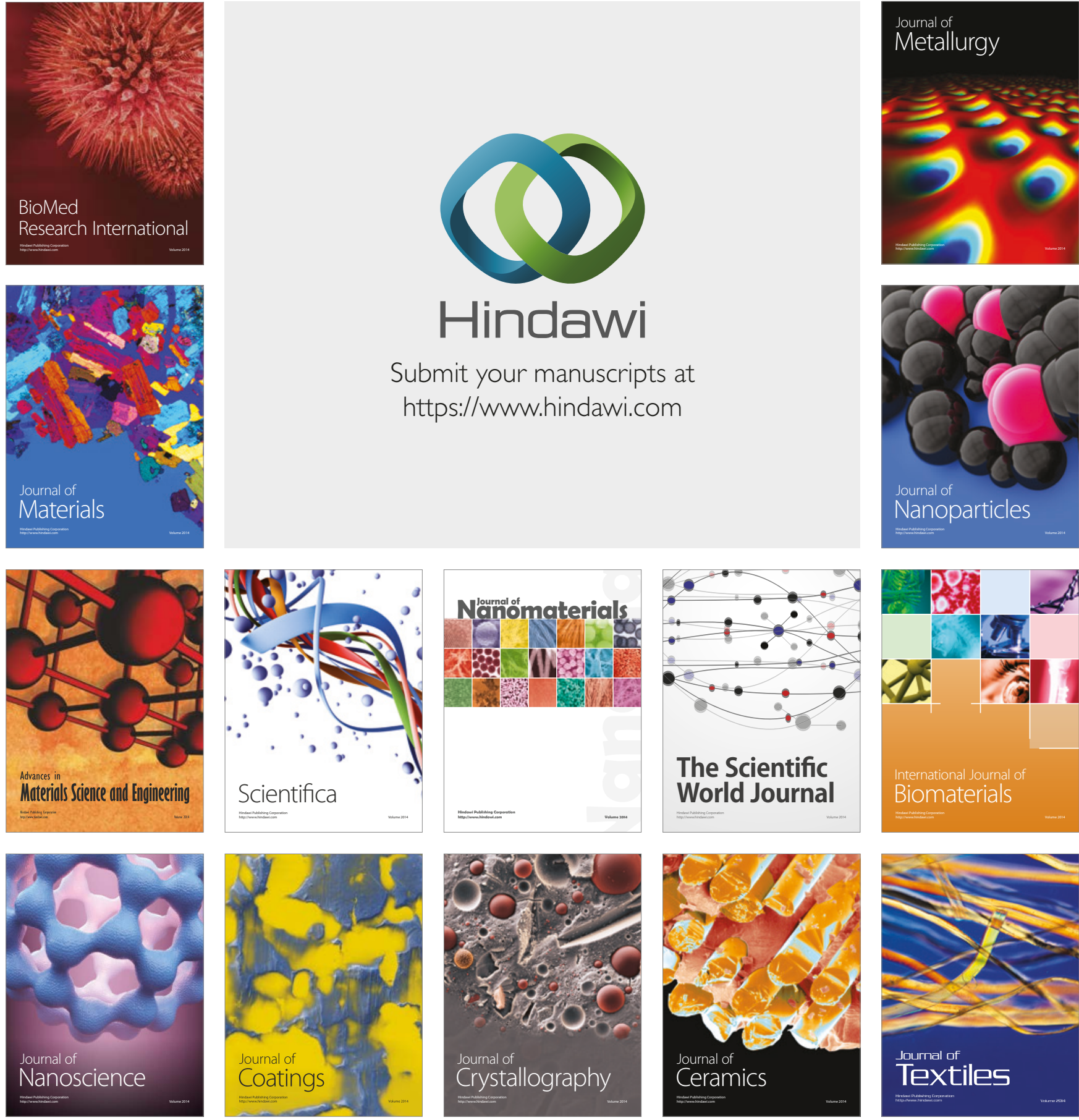

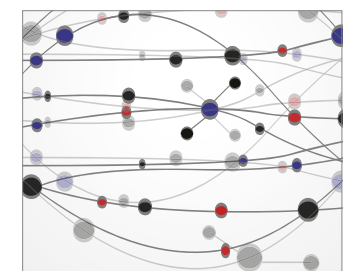

The Scientific World Journal
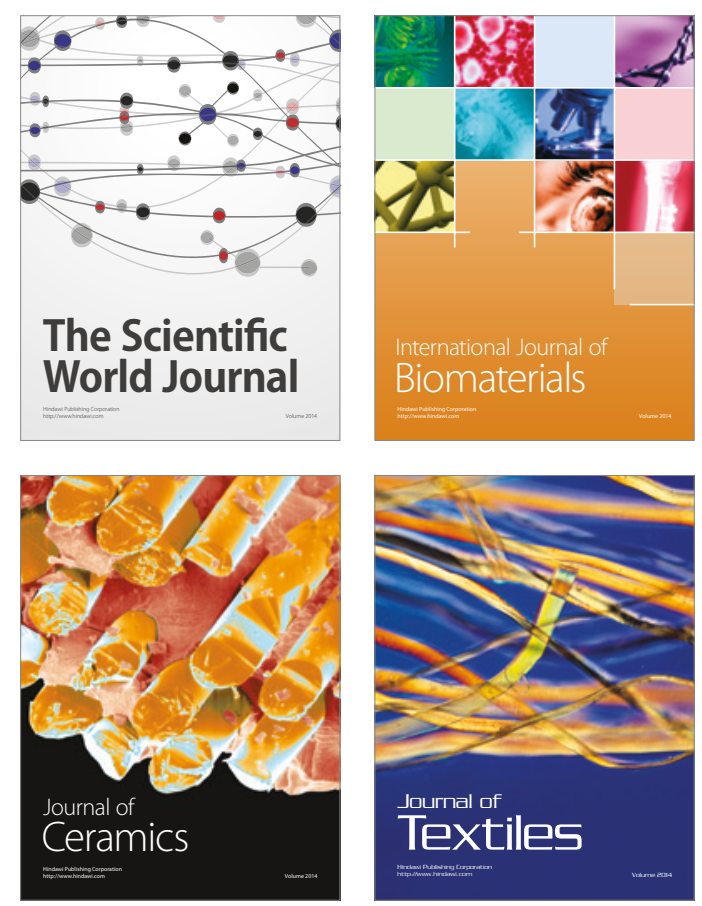